\title{
运用稳定碳同位素比值评价气源岩 理论潜在生气率*
}

\author{
陈红汉 孙永传 \\ (中国地质大学石油系, 武汉 430074) \\ 张启明张国华 \\ (南海西部石油公司, 湛江 524057)
}

\section{关链词 碳同位素比值 瑞利分馏 理论潜在生气率}

根据瑞利分馏过程导出动力学分馏因子 ${ }^{[1]}$ 和干酪根剩余分数, 从而运用气体碳同位素比 值直接计算动力学分馏因子和对气源岩理论潜在生气率进行评价, 并介绍一应用实例.

\section{1 原理}

有关天然气生气机理和碳同位素分馏机理, 前人已有广泛而深人的讨论 ${ }^{[2]}$. 为简单起见, 本文仅讨论干酪根热解直接生气过程的碳同位素效应.

分散于沉积物中的干酪根 (固相) 和热解生成的气体 (气相) 构成了一个非均相体系. 这个 过程中碳同位素效应主要受同位素质量、化学键、温度、化学反应和催化剂等因素影响, 并可 以用瑞利分馏方程加以描述,但基于下列条件:

（1）在同一温区内, 干酪根热解生气过程中碳同位素仅发生动力学分馏; (2) 气体碳同位 素变化仅依赖于干酪根碳同位素组成和剩余分数的变化; (3) 热解生成的气体要么溶解于间 隙水 (呈水相), 要么溶解于油 (呈油相), 或在不长的时间里从气源岩中排出, 从而使干酪根与 气体构成的体系可借用雨水凝聚过程的 “瞬间” 平衡开放体系来处理. 为此, 我们获得热解生 气阶段残留干酪根母质 ${ }^{13} \mathrm{C} /{ }^{12} \mathrm{C}$ 比值 $\left(R_{K}\right)$ 的瑞利分馏方程 ${ }^{(3)}$ :

$$
R_{K}=R_{K I} f^{k-1} \text {, }
$$

式中 $R_{K l}$ 为初始干酪根碳同位素比值, $f$ 是干酪根的剩余分数, $k$ 是动力学分馏因子. 用 $\delta$ 标 准定义:

则有

$$
\delta^{13} \mathrm{C}=\left(R / R_{\text {标准 }}-1\right) \cdot 1000 \% \text {, }
$$

和

$$
\delta^{13} \mathrm{C}_{K}=\left(R_{K} / R_{\text {标准 }}-1\right) \cdot 1000 \%
$$

$$
\delta^{13} \mathrm{C}_{K l}=\left(R_{K I} / R_{\text {标难 }}-1\right) \cdot 1000 \% .
$$

1994-09-08 收稿, 1995-01 -08 收修改稿

*国家自然科学基金资助项目 
由 (3) 式和 (4) 式分别得

$$
R_{K}=\left(1000+\delta^{13} \mathrm{C}_{K}\right) \cdot R_{\text {标准 }}
$$

和

$$
R_{K l}=\left(1000+\delta^{13} \mathrm{C}_{K l}\right) \cdot R_{\text {标准 }} \cdot
$$

将 (5) 式和 (6) 式代人 (1) 式, 经整理, 得

$$
\delta^{13} \mathrm{C}_{K}=\left(1000+\delta^{13} \mathrm{C}_{K I}\right) \cdot f^{K-1}-1000 .
$$

如果 $R_{\theta}$ 表示这一生气阶段气体总碳同位素比值, 根据质量守恒原量 ${ }^{[3]}$, 得

$$
R_{g}(1-f)+R_{K} f=R_{K l},
$$

由 (1)、(8) 式, 得

$$
R_{g}=R_{K I} \cdot\left(1-f^{K}\right) /(1-f)
$$

据 (2) 式将(9) 式改写成

$$
\delta^{13} \mathrm{C}_{g}=\left(1000+\delta^{13} \mathrm{C}_{K}\right) \cdot\left(1-f^{K}\right) /(1-f)-1000 .
$$

至此, 我们即获得了这一阶段烃类气体的总的 $\delta^{13} \mathrm{C}_{g}$ 与 $f, k$ 和 $\delta^{13} \mathrm{C}_{K l}$ 之间的函数关系式. 不妨令

$$
\begin{aligned}
& A=\left(1000+\delta^{13} \mathrm{C}_{K}\right) /\left(1000+\delta^{13} \mathrm{C}_{K l}\right), \\
& B=\left(1000+\delta^{13} \mathrm{C}_{g}\right) /\left(1000+\delta^{13} \mathrm{C}_{K l}\right) .
\end{aligned}
$$

则由 (7) 式, 得 .

$$
f=A^{1 /(K-1)},
$$

由 (10) 式, 得

$$
\left(1-f^{K}\right) /(1-f)=B
$$

将(13)式代人 (14)式, 经整理, 得

$$
B A^{1 /(K-1)}-A^{K(K-1)}=B-1 .
$$

令 $K=1+\frac{1}{X}$, 并代人 $(15)$ 式, 得

$$
X=\ln \frac{B-1}{B-A} / \ln A
$$

故有

$$
\begin{gathered}
K=1+\ln A / \ln \frac{B-1}{B-A}, \\
f=A^{\ln [(B-1) /(B-A)) / \ln A} .
\end{gathered}
$$

由于 $f$ 与干酪根成熟度有关, 因而, 只要规定一个生气指数 (GGI), 就很容易将 $f$ 与生气 程度联系起来 ${ }^{[3]}$, 即

$$
\text { 而 . } \begin{array}{r}
\mathrm{GGI}=1-f, \\
\mathrm{GGI}=Q_{g t} / Q_{t g},
\end{array}
$$

式中 $Q_{g t}$ 为已生成的全部气量 (用 $\%$ 表示), $Q_{t g}$ 为总的理论潜在生气率, 用百分数表示时可视 为单位 1 , 则由 (15) 和 (16) 式, 得

$$
Q_{g t}=1-f .
$$

我们知道, 千酪根潜在生气率 $\left(Q_{\theta p}\right)$ 是总理论潜在生气率与已生成的全部气量之差:

$$
Q_{g p}=1-Q_{g r}
$$


将(21) 式代人 (22) 式, 化简, 得

$$
Q_{g p}=f
$$

\section{2 应用实例}

南海北部大陆架西区的莺 - 琼盆地 (莺歌海盆地和琼东南盆地的简称, 两地以 (1) 号深大断 裂为界) 是在前白严系基底上发育起来的年轻海相沉积盆地. 自 70 年代大规模勘探以来, 在琼 东南盆地发现了迄今我国海上最大的 YA13-1 气田, 并相继在莺歌海盆地钻遇高产天然气藏 (如 DF1-1).

莺 - 琼盆地由于晚期 (始于上新世末) 的快速沉降, 最底部的崖城组 $\left(\mathrm{E}_{2+3 y}\right)$ 含煤系地层在 凹陷埋深逾万米. 钻井采集到 $5000 \mathrm{~m}$ 以上烃源岩是以耐热组分为主的 III 型干酪根为特 征.

天然气碳同位素分析样品分为 4 组 (表 1)：(1)YA13-1 气田气藏气, (2)YA21-1-1 井亚 生物气, (3) (1) 号断裂附近的气苗气, (4) 莺歌海盆地 (DF1-1 和 LD15-1 等) 气藏气. 除 YA21-1-1 井亚生物气之外, 其余均为中等一一近变质的热解气, 其中 DF1-1 气藏气成熟度最 高, YA13-1 气田气达到中 高成熟程度, 而 (1) 号断裂气苗气成熟度介于这二者之间.

表 1 莺 - 琼盆地天然气组分碳同位素分析 ${ }^{a)}$

\begin{tabular}{|c|c|c|c|c|c|c|c|c|}
\hline \multirow{2}{*}{$\begin{array}{l}\text { 盆 } \\
\text { 地 }\end{array}$} & \multirow{2}{*}{ 组 } & \multirow{2}{*}{ 类 型 } & \multicolumn{3}{|c|}{ 气体组分碳同位素比值 $/ \%$ PDB： } & \multicolumn{2}{|c|}{$\frac{\text { 平均值 }}{\text { 最小值 最大值 }}$} & \multirow{2}{*}{$\begin{array}{l}\text { 甲烷氢同位素 } \\
\text { D \% , SMOW }\end{array}$} \\
\hline & & & $\mathrm{C}_{1}$ & $\mathrm{C}_{2}$ & $\mathrm{C}_{3}$ & $\mathrm{C}_{4}$ & $\mathrm{CO}_{2}$ & \\
\hline 琼 & (1) & 气藏气 & $15 \frac{-37.46}{-39.88 \sim-34.4}$ & $9 \frac{-25.75}{-26.82 \sim-23.97}$ & $7 \frac{-25.27}{-27.71 \sim-24.2}$ & $4 \frac{-25.63}{-26.85 \sim-24.68}$ & $6 \frac{-7.23}{-10.29 \sim-4.9}$ & $5 \frac{-131.43}{-142.2 \sim-121.71}$ \\
\hline $\begin{array}{l}\text { 东 } \\
\text { 南 }\end{array}$ & (2) & 亚生物气 & $3 \frac{-55.0}{-60.8 \sim-49.5}$ & & & & $2 \frac{-20.95}{-25.5 \sim-16.4}$ & \\
\hline 营 & (3) & 气苗气 & $7 \frac{-36.04}{-38.3 \sim-33.9}$ & $1-23.0$ & & & & $1-148.5$ \\
\hline 海 & (4) & 气藏气 & $11 \frac{-34.78}{37.28 \sim 32.28}$ & $8 \frac{-25.05}{-27.1 \sim-21.05}$ & $7 \frac{-23.44}{-27.5 \sim-20.6}$ & $7 \frac{-22.69}{-25.8 \sim-19.24}$ & $8 \frac{-4.89}{-8.0 \sim-2.2}$ & $2 \frac{154.5}{-176 \sim-133}$ \\
\hline
\end{tabular}

a) 中国科学院兰州地质研究所测定

考虑到同位素动力学分馏因子 $(K)$ 受到分子量的影响 (在相同条件下, 分子量越大, $K$ 越接 近 1 , 即趋向于无分馏) 和生气母质基团在生物合成中的同位素效应, 对于丁烷, 其 $\Delta \delta^{13} \mathrm{C}=$ $\delta^{13} \mathrm{C}_{K}-\delta^{13} \mathrm{C}_{4}=1 \% 0 \sim 2 \%{ }^{[1]}$, 根据表 1数据推算出 DF1-1 气藏气源岩干酪根 $\delta^{13} \mathrm{C}_{K}=$ $-24.8 \% 0 \sim-17.24 \% 0$. 而由表 2 给出其可能烃源岩干酪根的实测平均值 $\delta^{13} \mathrm{C}_{K}=-24.28 \%$, 正好处于上述范围之中, 由此表明 DF1-1 气藏的气源岩位于莺黄组和梅山组及其下部地层. 若假设气源岩初始干酪根碳同位素比值 $\delta^{13} \mathrm{C}_{K I}=-28 \%{ }^{[4]}$, 由于烃类气体组分中 $90 \%$ 以上是甲 烷, 而 $\delta^{13} \mathrm{C}_{g} \approx \delta^{13} \mathrm{C}_{1}=-32.28 \%$, 根据 (11)、(12)式分别算得 DF1-1 气藏气的 $A=1.0038, B=$ 0.9956 , 又由 (18)、(19) 式分别求出碳同位素动力学分馏因子 $K=0.99389$, 干酪根剩余分数 $f=0.5350$. 这表明 DF $1-1$ 气田最高成熟度烃类气体来自深埋的气源岩, 具体埋深取决于温 度场的分布, 在 LD30-1-1A 地区 (地温梯度为 $4.5^{\circ} \mathrm{C} / 100 \mathrm{~m}$ ), 由 (23) 式算得莺黄组和梅山组 的气源岩至今仍具有约 $53.5 \%$ 的理论潜在生气率.

对于 YA13-1 气田, 在 3920 3 $393 \mathrm{~m}$ 埋深内测得到 $\delta^{13} \mathrm{C}_{K}$ 平均值为 $-27.31 \%$. 若最高 
表 2 营 - 琼盆地烃源岩煤油抽提干酪根碳同位素比值 $\left(\delta^{13} \mathrm{C} \% 0\right)^{\mathrm{a})}$

\begin{tabular}{|c|c|c|c|c|}
\hline 盆 地 & 号 & 层 位 & 深 $/ \mathrm{m}$ & 碳同位表比值 $/ \% 0$, PDB \\
\hline \multirow{2}{*}{ 琼东南 } & YA13-1-2 & 崖城组 & $3920 \sim 3923$ & -27.26 \\
\hline & YA19-1-1 & 梅山组 & $3989.0 \sim 3992.9$ & -27.38 \\
\hline \multirow{2}{*}{ 掌歌海 } & \multirow{2}{*}{ LD30-1-1A } & 虽 - 黄组 & 2511.5 & -24.16 \\
\hline & & 梅山组 & 4700 & -24.41 \\
\hline
\end{tabular}

a) 数据来源同表 1

成熟度的烃类气体 $\delta^{13} \mathrm{C}_{g} \approx \delta^{13} \mathrm{C}_{1}=-34.5 \%$, 同上理, 计算求得其气源岩干酪根分馏因子 $K=0.99307$, 干酪根剩余分数 $f=0.90268$. 也就是说, 在此深度范围烃源岩仍保持着约 $90 \%$ 的理论潜在生气率. 由此可见, YA13-1 气田高成熟度天然气肯定来自于侧向埋藏更深的气 源岩 (另文).

需要指出的是, 上述计算分馏因子和评价气源岩理论潜在生气率的方法受到确定气源岩 干酪根碳同位素比值 $\left(\delta^{13} \mathrm{C}_{K}\right)$ 和其初始干酪根碳同位素比值 $\left(\delta^{13} \mathrm{C}_{K I}\right)$ 的约束. 有关 $\delta^{13} \mathrm{C}_{K}$ 对 $K$ 和 $f$ 的影响可通过实测或气源对比研究而加以框定, 而由 $\delta^{13} \mathrm{C}_{K l}$ 引起的计算误差也是非常显著 的. 譬如, 上述 DF1-1 气田, 假定 $\delta^{13} \mathrm{C}_{K l}=-27 \%$, 则造成动力学分馏因子的差值 $\Delta K=-0.06 \%$, 理论潜在生气率的差值 $\Delta f=12.5 \%$, 即 $\delta^{13} \mathrm{C}_{K I}$ 增加一个 PDB 单位, 则 $K$ 减少 0.006 , 而 $f$ 增加 0.125. 限于篇幅, 有关 $\delta^{13} \mathrm{C}_{K I}$ 对 $f$ 和 $K$ 的误差估计的定量推导以及 $\delta^{13} \mathrm{C}_{g}$ 和 $f$ 的图示将另文给 出.

致谢感谢南海西部石油公司研究院蔡世详科长和黄荣家同志在工作中给予的大力支 持.

\section{参 考 文 献}

1 Clayton C. Carbon isotope fractionation during natural gas generation from Kerogen. Marine and Petroleum, 1991, 8: $232 \sim 240$

2 Smith J W, Rigby D, Gould $\mathrm{K}$ W et al. An isotopic study of hydrocarbon generation procsses. Organic Geochemistry, 1985, 8:341 347

3 郑淑感, 郑斯成, 莫志超. 稳定同位素地球化学分析. 北京: 北京大学出版社, 1986

4 傅家谟,刘德汉,盛国英等. 煤成烃地球化学. 北京: 科学出版社, 1990 